\title{
Heterogeneous effects of the SEC's Securities Offering Reform
}

\author{
Danial R. Hemmings* \\ Bangor Business School, Bangor University \\ Lynn Hodgkinson \\ Bangor Business School, Bangor University \\ Qingwei Wang \\ Cardiff Business School, Cardiff University
}

\begin{abstract}
The SEC's Securities Offering Reform (SOR) was intended to address information problems prior to Seasoned Equity Offerings (SEO), thereby mitigating the problem of SEO overpricing. Consistent with the propensity of overpricing increasing with idiosyncratic stock return volatility (IVOL), we find greater capital market benefits from SOR for high IVOL issuers. Counter to concerns that SOR also enables issuers to hype their stock, we find no evidence of market conditioning following SOR, even among high IVOL issuers.
\end{abstract}

Keywords: Securities Offering Reform, Seasoned Equity Offerings, Idiosyncratic Volatility, Market Conditioning.

JEL Codes: G14, G32, G38, M40

${ }^{*}$ Corresponding author. Address for correspondence: Danial R. Hemmings, Bangor Business School, Hen Goleg, College Road, Bangor, UK, LL57 2DG. Phone: +44 0124838 8162. E-mail: d.hemmings@bangor.ac.uk 


\section{Introduction}

This paper investigates whether the effects of the SEC's Securities Offering Reform (SOR) on share price efficiency at the time of Seasoned Equity Offerings (SEOs) varies with idiosyncratic stock return volatility (IVOL). Enacted in late 2005, SOR relaxed historic gunjumping restrictions, which prohibited certain information disclosures prior to SEOs. The gunjumping provisions were intended to protect investors from market conditioning, ${ }^{1}$ however they also prevented the timely dissemination of accurate information demanded by investors. ${ }^{2}$ Thus, while SOR may yield improvements in market efficiency, via an enhancement in the preSEO disclosure environment, it may also enable firms to engage in greater market conditioning. Since the propensity for mispricing varies across stocks, we examine for differences in the effects of SOR based on IVOL, since the propensity for mispricing is expected to be greater for high IVOL stocks.

A long literature documents the apparent propensity for SEOs to coincide with overpricing of issuers' stock (Baker \& Wurgler, 2012; Wang et al., 2013). In particular, SEOs are preceded by pronounced share price appreciation, and followed by return underperformance. An enhanced pre-SEO information environment can promote greater stock price efficiency, thereby reducing the scope for mispricing by the market. Increased disclosure levels are associated with reductions in information asymmetry (Diamond \& Verrecchia, 1991) and information risk (Healy and Palepu, 2001). The availability of better information should reduce the propensity for speculation in the market (Baker \& Wurgler, 2006) and bring stock prices closer to fundamental values (Gao, 2008). Following SOR, Clinton et al. (2014) find significant improvements in the pre-SEO information environment, including increases in disclosure volumes and quality, and that SOR led to capital formation benefits. Similarly, Shroff et al. (2013) find that SOR reduced information asymmetry, and consequently, issuers' cost of capital.

The capital market benefits of SOR, however, should not be homogeneous across issuers, as assumed by Clinton et al. (2014) and Shroff et al. (2013), since the underlying probability of overpricing is not constant for all stocks. In particular, speculative stock attributes, such as high IVOL, attract retail investors who have a greater propensity to gamble (Kumar, 2009; Han \&

\footnotetext{
${ }^{1}$ Opponents of the reform feared that greater discretion over the release of pre-SEO disclosures would enable issuers to engage in market conditioning, or 'hyping', whereby self-touting voluntary disclosures are used to increase investor demand for the offering (Morrissey, 2006).

${ }^{2}$ See the Securities Offering Reform Final Rule at http://www.sec.gov/rules/final/33-8591.pdf.
} 
Kumar, 2013). IVOL also acts as a pervasive constraint on arbitrage activity, which may otherwise correct prices towards fundamental values. Indeed, Pontiff (2006, p. 49) argues that IVOL “appears to be the single largest impediment to market efficiency". To the extent that SOR led to improvements in market efficiency, we hypothesise, and show, that the benefits of SOR are greater for issuers with higher IVOL.

Furthermore, since market conditioning relates to the elicitation of increased investor demand through overly-optimistic pre-SEO disclosures (Lang \& Lundholm, 2000), notable price effects are more likely for stocks with a greater propensity for mispricing. Shroff et al. (2013) conduct tests for systematic effects of market conditioning, without adjustment for expected differences in the propensity for mispricing, and obtain insignificant results but which do "[point] in the direction of hyping" (p. 1324). They concede that their tests suffer from low power. As an additional test, therefore, we examine the impact of SOR on market conditioning, taking IVOL into account.

Our study makes two main contributions to the literature. First, we add to a handful of papers examining the impact of SOR, and, to our knowledge, we are the first to examine how the effects of the reform vary with speculative stock attributes. Importantly, we demonstrate that the benefits of SOR for high IVOL stocks are likely to be greater than previously demonstrated. Secondly, we contribute to the literature on opportunistic disclosure by testing for market conditioning by conducting tests which account for IVOL. Counter to commentators' concerns (e.g., Morrissey, 2006), we find no evidence of market conditioning following the reform, even for high IVOL stocks.

\section{Data}

We obtain a sample of SEOs (public offers) announced between January 1, 2000, and December 31, 2011, from the Bloomberg New Issues database. The Securities Offering Reform became effective on December 1, 2005, approximately mid-way through the sample period. We exclude rights-offerings and pure secondary offerings from the sample. We obtain issuers' CIK codes from Thomson One Banker, and use these to merge with 8-K filings data from EDGAR. We obtain firm-level returns and financial data from Datastream and Worldscope, respectively. Fama-French factors are obtained from Kenneth French's website. The final sample consists of 2,653 SEO announcements.

\section{Methodology}




\subsection{Key variable definitions}

We estimate abnormal returns using the Fama-French three factor model as our benchmark model for expected returns, similarly to Teoh et al. (1998). We estimate Eq. (1) over a 12month estimation window for each event, between 18 months and 6 months prior to the SEO announcement $(\mathrm{t}=-391,-131)$ :

The abnormal return (AR) for company $i$ is given by:

We then measure cumulative abnormal returns (CAR) as follows:

Where $(\mathrm{t}=\mathrm{n}, \mathrm{t}=\mathrm{m})$ is the event window. We apply both pre-SEO $(-130,-6)$ and post-SEO $(+6$, $+391)$ event windows within our analyses, where $(t=0)$ is the SEO announcement date.

Heterogeneous effects of the reform are examined by taking into account the prevailing idiosyncratic volatility of issuers' stock (IVOL). We measure IVOL as the root mean squared error (RMSE) of Eq. (1), as per Eq. (4) below:

High values of $I V O L$ are associated with higher information uncertainty (Barth et al., 2017), and greater arbitrage constraints (Pontiff, 2006). Stocks with high levels of IVOL are therefore expected to be more prone to mispricing. We expect improvements in price efficiency following the reform to be most pronounced for high $I V O L$ stocks.

In order to test for market conditioning (stock hyping) by issuers releasing overly-optimistic pre-SEO disclosures, we first measure $S R E T_{d}$ as the CAR over the three-day window $(-1,+1)$ around each discretionary $8-\mathrm{K}$ disclosure made in the 6-month pre-SEO window. Similarly to Shroff et al. (2013), we base our tests for market conditioning on Sum of SRET $T_{d}$, being the aggregate $S R E T_{d}$ for all pre-SEO discretionary disclosures by the issuer. It is suggested by Lang 
and Lundholm (2000), Rogers et al. (2011), and Huang et al. (2014) that firms are incentivised to opportunistically manage discretionary disclosures.

We estimate the mean value of Sum of $S R E T_{d}$ to be significantly positive at $1.17 \%$ (T-stat $=$ 4.50). Higher values of Sum of $S R E T_{d}$, however, do not necessarily reflect market conditioning, as fundamental information may simply be better for some issuers. We therefore orthogonalize Sum of SRET $T_{d}$ to returns on issuers' mandatory 8-K disclosures (Sum of SRET $T_{m}$ ), as well as a number of firm-level financial indicators and industry-year fixed effects. Our final measure of market conditioning (CONDT) is the residual ( ) from cross-sectional regressions of Eq. (5) below:

In order to control for issuers' fundamentals, Eq. (5) includes: market-to-book ratio $(M / B)$, logarithm of market value of equity (Size), return on assets ratio $(R O A)$, and Tobin's Q $(T Q)$, all at the most recent year-end prior to the offering announcement. If pre-SEO discretionary disclosures are overly positive, then we expect Sum of SRET $T_{d}$ to be higher than predicted by the model (Eq. 5), and therefore the residual (CONDT) would be positive.

\subsection{Empirical models}

We evaluate the capital market benefits of SOR by examining whether the reform mitigates pre-SEO stock price run-ups, and post-SEO return reversal, commonly thought to be hallmarks of SEO overpricing. We therefore model the pre-SEO $(-130,-6)$ and post-SEO $(+6,+391)$ CAR using the following multiple regression models:

Eq. (6) relates to the pre-SEO CAR, while Eq. (7) relates to the post-SEO CAR, including the possible reversal of market conditioning in pre-SEO disclosures (CONDT). We test possible effects of SOR by inclusion of a Postref dummy variable, equal to 1 (0) for SEO announcements made after (up to and including) 2005, as well as a series of interactions. Both models include controls for: market-to-book ratio $(M / B)$, logarithm of market value of equity 
(Size), return on assets ratio $(R O A)$, and Tobin's Q $(T Q)$, all at the most recent year-end prior to the offering announcement, as well as industry fixed effects. We also employ alternative restricted specifications of Eq. (6) and Eq. (7) in our analyses.

\section{Results}

We present the results for the impact of SOR on pre-SEO returns in Table 1. The reduced model in column (1) shows that the reform was associated with a significant overall reduction in the pre-SEO CAR by approximately $4.8 \%$ over the six-month pre-SEO announcement period. Thus, if the pre-SEO share price run-up is reflective of SEO overpricing, this suggests that the reform led to an overall increase in price efficiency. The results in columns (2)-(3) however demonstrate that, as predicted, the effects of the reform are greater for issuers with higher IVOL. Specifically, we observe a positive and significant coefficient on IVOL in column (3), consistent with the notion that high IVOL stocks experienced a greater pre-SEO run-up prior to the reform, however we also find a negative coefficient on the Postref*IVOL interaction, significant at the $10 \%$ level, which suggests smaller differences between high and low IVOL stocks following the reform.

\section{[Insert Table 1 about here]}

We present results from regressions on the post-SEO CAR (firstly, excluding CONDT and its interactions) in Table 2. The reduced model in column (2) reports a significantly negative coefficient on IVOL, consistent with the notion that high IVOL issuers experience greater overpricing, and thus a more pronounced reversal following the SEO. The negative coefficient on Postref in columns (1) and (3), however, suggests that average post-SEO return performance across issuers has deteriorated following the reform. This may reflect a greater reduction in issuers' cost of capital, given the richer information environment facilitated by the reform (Clinton et al., 2014). In model (3) of Table 2, we observe a positive and significant coefficient on the Postref*IVOL interaction, which, taken together with the negative coefficient on this term in column (3) of Table 1, suggests that overpricing of high IVOL stocks at SEO is reduced after the reform.

\section{[Insert Table 2 about here]}

In order to test for the effects of the reform on market conditioning, we estimate the full specification of Eq. (7) and present the results in Table 3. In columns (1) and (2), before including IVOL and its interactions, we obtain results consistent with Shroff et al. (2013), i.e., 
no significant evidence of return reversal to CONDT in the aggregate. In column (4), we include interactions with $I V O L$ to examine whether the results differ across this dimension. Since the full specification of Eq. (7) contains numerous interactions, we compute marginal effects of CONDT at representative values of $I V O L$ to aide interpretation. Specifically, we estimate the marginal effects of CONDT following the reform, when $I V O L$ situates on the $25^{\text {th }}, 50^{\text {th }}$, and $75^{\text {th }}$ percentiles. ${ }^{3}$ In each case, we estimate the marginal effect of CONDT to be insignificantly positive, indicating no reversal of the abnormal return on pre-SEO filings, regardless of the level of IVOL.

[Insert Table 3 about here]

\section{Conclusions}

We examine whether the effects of the SEC's Securities Offering Reform (SOR) differ depending on issuers' idiosyncratic volatility (IVOL). The reform introduced a more relaxed pre-SEO disclosure environment, which yielded a richer information environment (Clinton et al., 2014). We show that the informational benefits of the reform, in terms of more efficient market pricing, is greater for firms with higher IVOL. Higher IVOL is associated with greater information uncertainty (Barth et al., 2017), higher proportion of speculative investor types (Han \& Kumar, 2013), and greater arbitrage constraints (Pontiff, 2006), and thus high IVOL stocks are more prone to overpricing. Importantly, our results indicate that the benefits of SOR for high IVOL issuers are likely to be greater than previously thought. Counter to commentators' concerns, we find no evidence of issuers exploiting the flexibility afforded by conditioning the market, even when IVOL is high. While our tests for market conditioning are arguably more powerful than those of Shroff et al (2013), they are still limited in the sense that they do not consider disclosures' qualitative characteristics. Overall, our findings contribute to the limited literature which demonstrates the beneficial effects of SOR.

\footnotetext{
${ }^{3}$ We calculate marginal effects as the sum of the coefficients on CONDT and Postref*CONDT plus the coefficients on $I V O L^{*} C O N D T$ and Postref*IVOL ${ }^{*} C O N D T$ multiplied by the value of $I V O L$ at the $25^{\text {th }}, 50^{\text {th }}$, and $75^{\text {th }}$ percentile $(I V O L=1.54,2.44$, and 3.78). T-statistics presented below marginal effects are estimated using the delta-method.
} 


\section{References}

Baker, M., Wurgler, J., 2006. Investor sentiment and the cross-section of stock returns. The Journal of Finance, 61(4), 1645-1680.

Baker, M., Wurgler, J., 2012. Behavioral corporate finance: an updated survey, in Constantinides, G., Harris, M., \& Stulz, R. (eds) Handbook of the Economics of Finance: Volume 2, Elsevier: New York.

Barth, M. E., Landsman, W. R., Taylor, D. J., 2017. The JOBS Act and information uncertainty in IPO firms. The Accounting Review, 92(6), 25-47.

Clinton, S.B., White, J.T., Woidtke, T., 2014. Differences in the information environment prior to seasoned equity offerings under relaxed disclosure regulation. Journal of Accounting and Economics, 58(1), 59-78.

Diamond, D. W., Verrecchia, R. E., 1991. Disclosure, liquidity, and the cost of capital. The Journal of Finance, 46(4), 1325-1359.

Gao, P., 2008. Keynesian beauty contest, accounting disclosure, and market efficiency. Journal of Accounting Research, 46(4), 785-807.

Han, B., Kumar, A., 2013. Speculative retail trading and asset prices. Journal of Financial and Quantitative Analysis, 48(2), 377-404.

Healy, P. M., Palepu, K. G., 2001. Information asymmetry, corporate disclosure, and the capital markets: A review of the empirical disclosure literature. Journal of Accounting and Economics, 31(1), 405-440.

Huang, X., Teoh, S.H., Zhang, Y., 2014. Tone management. The Accounting Review, 89(3), 1083-1113.

Kumar, A., 2009. Who gambles in the stock market?. The Journal of Finance, 64(4), 18891933.

Lang, M.H., Lundholm, R.J., 2000. Voluntary disclosure and equity offerings: reducing information asymmetry or hyping the stock?. Contemporary Accounting Research, 17(4), 623662.

Morrissey, J.F., 2006. Rhetoric and reality: Investor protection and the securities regulation reform of 2005. Catholic University Law Review, 56, 561-607.

Pontiff, J., 2006. Costly arbitrage and the myth of idiosyncratic risk. Journal of Accounting and Economics, 42(1), 35-52.

Rogers, J.L., Van Buskirk, A., Zechman, S.L., 2011. Disclosure tone and shareholder litigation. The Accounting Review, 86(6), 2155-2183. 
Shroff, N., Sun, A.X., White, H.D., Zhang, W., 2013. Voluntary disclosure and information asymmetry: Evidence from the 2005 securities offering reform. Journal of Accounting Research, 51(5), 1299-1345.

Teoh, S.H., Welch, I., Wong, T.J., 1998. Earnings management and the underperformance of seasoned equity offerings. Journal of Financial Economics, 50(1), pp.63-99.

Wang, C.Y., Chen, Y.F., Yu, C.W., 2013. Managerial optimism and post-financing stock performance in Taiwan: A comparison of debt and equity financing. Economics Letters, 119(3), pp.332-335. 
Table 1

Regressions on pre-SEO cumulative abnormal returns (-6 to 0 months).

\begin{tabular}{llll}
\hline & $(1)$ & $(2)$ & $(3)$ \\
\hline Intercept & $82.232^{* * *}$ & $74.092^{* * *}$ & $71.830^{* * *}$ \\
Postref & $(9.15)$ & $(7.37)$ & $(7.02)$ \\
& $-4.802^{* * *}$ & & 0.700 \\
IVOL & $(-3.66)$ & & $(0.27)$ \\
& & 0.919 & $2.256^{* *}$ \\
Postref*IVOL & & $(1.39)$ & $(2.23)$ \\
& & & $-2.009^{*}$ \\
Size & $-4.806^{* * *}$ & $-4.576^{* * *}$ & $(-1.86)$ \\
& $(-9.54)$ & $(-8.46)$ & $-4.442^{* * *}$ \\
M/B & 0.126 & 0.139 & $(-8.14)$ \\
& $(0.85)$ & $(0.95)$ & 0.099 \\
ROA & $13.238^{* *}$ & $17.248^{* * *}$ & $(0.68)$ \\
& $(2.29)$ & $(2.88)$ & $15.441^{* * *}$ \\
TQ & $2.262^{* * *}$ & $2.395^{* * *}$ & $(2.65)$ \\
& $(3.72)$ & $(3.92)$ & $2.150^{* * *}$ \\
Industry FE & & & $(3.59)$ \\
R-squared & Yes & Yes & Yes \\
N & 0.12 & 0.12 & 0.12 \\
\hline
\end{tabular}

Our sample covers 2,653 Seasoned Equity Offerings between 2000 and 2011, where Postref is a dummy variable equal to 1 (0) for SEO announcements made after (up to and including) 2005. $T$-statistics are shown in parentheses below coefficient estimates, and are based on robust standard errors clustered at the firm level. $*, * *$, and ${ }^{* * *}$ denote significance at the $10 \%, 5 \%$, and $1 \%$ levels, respectively, based on a two-tailed test. 


\section{Table 2}

Regressions on post-SEO cumulative abnormal returns ( 0 to +18 months).

\begin{tabular}{llll}
\hline & $(1)$ & $(2)$ & $(3)$ \\
\hline Intercept & -2.222 & $44.208^{* * *}$ & $49.321^{* * *}$ \\
Postref & $(-0.16)$ & $(2.89)$ & $(3.17)$ \\
& $-5.026^{* *}$ & & $-21.653^{* * *}$ \\
IVOL & $(-2.09)$ & & $(-4.22)$ \\
& & $-5.640^{* * *}$ & $-9.339^{* * *}$ \\
Postref*IVOL & & $(-5.58)$ & $(-5.51)$ \\
& & & $6.268^{* * *}$ \\
Size & & & $(3.42)$ \\
& & $-2.664^{* * *}$ & $-2.280^{* * *}$ \\
M/B & $(-0.178$ & $(-3.13)$ & $(-2.65)$ \\
& -0.422 & -0.310 & -0.300 \\
ROA & $(-1.43)$ & $(-1.08)$ & $(-1.06)$ \\
& $28.428^{* * *}$ & 14.334 & $15.350^{*}$ \\
TQ & $(3.01)$ & $(1.57)$ & $(1.70)$ \\
& $-3.620^{* * *}$ & $-3.584 * * *$ & $-3.293^{* * *}$ \\
Industry FE & $(-3.36)$ & $(-3.47)$ & $(-3.21)$ \\
R-squared & & & Yes \\
$\mathrm{N}$ & Yes & Yes & 0.12 \\
\hline
\end{tabular}

Our sample covers 2,653 Seasoned Equity Offerings between 2000 and 2011, where Postref is a dummy variable equal to 1 (0) for SEO announcements made after (up to and including) 2005. $T$-statistics are shown in parentheses below coefficient estimates, and are based on robust standard errors clustered at the firm level. $*, * *$, and $* * *$ denote significance at the $10 \%, 5 \%$, and $1 \%$ levels, respectively, based on a two-tailed test. 
Table 3

Regressions on post-SEO CAR: Tests for market conditioning

Dependent variable: Post-SEO cumulative abnormal returns ( 0 to +18 months $)$

\begin{tabular}{|c|c|c|c|c|}
\hline & (1) & (2) & (3) & (4) \\
\hline \multirow[t]{2}{*}{ Intercept } & -4.238 & -3.900 & $42.404 * * *$ & $48.687 * * *$ \\
\hline & $(-0.30)$ & $(-0.28)$ & $(2.79)$ & $(3.23)$ \\
\hline \multirow[t]{2}{*}{ CONDT } & 0.148 & 0.024 & -0.224 & $-0.915 * *$ \\
\hline & $(1.46)$ & $(0.13)$ & $(-1.00)$ & $(-2.31)$ \\
\hline \multirow[t]{2}{*}{ Postref*CONDT } & & 0.187 & & $0.850 *$ \\
\hline & & $(0.83)$ & & $(1.85)$ \\
\hline \multirow[t]{2}{*}{$I V O L * C O N D T$} & & & $0.082 *$ & $0.229 * *$ \\
\hline & & & $(1.71)$ & $(2.57)$ \\
\hline \multirow[t]{2}{*}{ Postref*IVOL *CONDT } & & & & $-0.171^{*}$ \\
\hline & & & & $(-1.66)$ \\
\hline \multirow[t]{2}{*}{ Postref } & & $-5.137 * *$ & & $-23.424 * * *$ \\
\hline & & $(-2.14)$ & & $(-5.22)$ \\
\hline \multirow[t]{2}{*}{$I V O L$} & & & $-5.584 * * *$ & $-9.885 * * *$ \\
\hline & & & $(-5.83)$ & $(-7.47)$ \\
\hline \multirow[t]{2}{*}{ Postref*IVOL } & & & & $6.911 * * *$ \\
\hline & & & & $(4.41)$ \\
\hline \multirow[t]{2}{*}{ Baseline } & 0.109 & 0.114 & 0.106 & 0.102 \\
\hline & $(1.07)$ & $(1.11)$ & $(1.07)$ & $(1.02)$ \\
\hline \multirow[t]{2}{*}{ Size } & -0.276 & -0.101 & $-2.590 * * *$ & $-2.167 * *$ \\
\hline & $(-0.33)$ & $(-0.12)$ & $(-3.06)$ & $(-2.53)$ \\
\hline \multirow[t]{2}{*}{$M / B$} & -0.400 & -0.430 & -0.308 & -0.283 \\
\hline & $(-1.35)$ & $(-1.45)$ & $(-1.07)$ & $(-0.99)$ \\
\hline \multirow[t]{2}{*}{$R O A$} & $29.372 * * *$ & $27.673 * * *$ & 13.714 & 13.468 \\
\hline & $(3.12)$ & $(2.92)$ & $(1.50)$ & $(1.48)$ \\
\hline \multirow[t]{2}{*}{$T Q$} & $-3.479 * * *$ & $-3.630 * * *$ & $-3.583 * * *$ & $-3.355 * * *$ \\
\hline & $(-3.22)$ & $(-3.36)$ & $(-3.47)$ & $(-3.24)$ \\
\hline Industry FE & Yes & Yes & Yes & Yes \\
\hline R-squared & 0.08 & 0.08 & 0.11 & 0.12 \\
\hline $\mathrm{N}$ & 2,653 & 2,653 & 2,653 & 2,653 \\
\hline
\end{tabular}

Marginal effect of CONDT after the reform (i.e., Postref $=1$ ):

Low IVOL: $25^{\text {th }}$ percentile $\quad 0.025$

Med IVOL: $50^{\text {th }}$ percentile $\quad(0.14)$

$0.51)$
$(0.518$

High IVOL: $75^{\text {th }}$ percentile $\quad 0.156$

(1.29)

Our sample covers 2,653 Seasoned Equity Offerings between 2000 and 2011, where Postref is a dummy variable equal to 1 (0) for SEO announcements made after (up to and including) 2005. $T$-statistics are shown in parentheses below coefficient estimates, and are based on robust standard errors clustered at the firm level. 
$*, * *$, and $* * *$ denote significance at the $10 \%, 5 \%$, and $1 \%$ levels, respectively, based on a two-tailed test. 